\title{
New Normal Set-up on Safety and Health Standards in Government Construction Projects: A case of Covid-19
}

\author{
Noel T. Florencondia, Rhizza Mae B. Lansangan, Ericka V. Marcos, John Vincent L. Santos, Keith \\ Russel E. Soriano
}

\begin{abstract}
The New Normal Set-up on Safety and Health Standards in Government Construction Projects during this time of the Covid-19 pandemic is a new guideline or protocol on construction sites in preventing the spread of the coronavirus disease within the construction workers in Central Luzon before, during, and after construction activities. This study aims to verify the effectivity of the New Normal Set-up on safety and health protocol in preventing the spread of the virus during a pandemic crisis. This paper will provide an assessment, evaluation, and recommendations on the current mandated rules of government agencies within Central Luzon in terms of safety and health guidelines in the implementation of construction projects during this Covid-19 public health crisis.

Keywords: Covid-19 pandemic, Construction, Safety and Health Standards
\end{abstract}

\section{INTRODUCTION}

Philippine Government construction projects bring benefit in boosting its economy and in mitigating the lives of Filipino citizen: giving better transportation system, water supply, and irrigation facilities, educational, recreational, and health infrastructures that help improve the quality of living, attract more investments, potential to create jobs and enhance the productivity around the country. However, the latest Covid-19 pandemic has had a significant effect on and temporarily stalled the execution of infrastructure programs.

To stop the transmission of this infectious disease among workers, the building industry must accept new ways of working and continuously adapt to the new normal set-up of occupational safety and health standards.Providing safety and health protocols, especially in Central Luzon, has been a major challenge for all government implementing offices.Construction workers, in particular, are notoriously stubborn when it comes to adhering to construction safety standards. As a result, project managers must ensure that all of their employees are narrowly focused and advised on

Manuscript received on June 13, 2021.

Revised Manuscript received on June 19, 2021.

Manuscript publishedon June 30, 2021.

* Correspondence Author

Noel T. Florencondia, Professor, Nueva Ecija University of Science and Technology, Nueva Ecija, Philippines.

Rhizza Mae B. Lansangan, Senior Engineer, A National Irrigation Administration - UPRIIS Division V, Nueva Ecija, Philippines.

Ericka V. Marcos, Instructor, Araullo University - Phinma Education Network, Nueva Ecija, Philippines.

John Vincent L. Santos*, Lecturer, Holy Cross College, Nueva Ecija, Philippines.

Keith Russel E. Soriano, Senior Engineer, A National Irrigation Administration - UPRIIS Division IV , Nueva Ecija, Philippines

(C) The Authors. Published by Blue Eyes Intelligence Engineering and Sciences Publication (BEIESP). This is an open access article under the CC BY-NC-ND license (http://creativecommons.org/licenses/by-nc-nd/4.0/) social distancing guidelines, as well as introducing new sanitation and personal protective equipment (PPE) programs as an additional safety policy in the construction.

The stringent implementation of health and quarantine procedures demonstrates the value of providing an effective new normal set-up for government departments that control construction programs during a pandemic. The results of this study will help the construction industry by revealing potential courses of action for keeping employees safe and the project running during a pandemic. This research could lead to new safety and health requirements in government construction projects.

The research aims to answer the following questions:

- Is the current mandated rules by different government agencies on safety and health protocols enough to avoid the spread of the Covid-19 disease within the construction workers?

- Does government project managers within Central Luzon strictly executing the safety and health guidelines in the project site.

\section{LITERATURE REVIEW}

Construction has been greatly impacted by COVID-19, but it is crucial to the post-COVID economic growth and recovery. Construction, in particular, must maintain consistent awareness of protection and risk-balancing when delivering projects on schedule. COVID-19 guidance must then be applied in a manner that represents working practices and stresses. However, there could be an expertise deficit about the functional viability and effect of implementing COVID-19 steps in construction, which is intensified by considerations such as the contractual existence of projects and complicated working arrangements. The main point is that COVID-19 should be incorporated and promoted as part of a broader risk management strategy, in part because this takes into account differing expectations for safety threats rather than overly relying on COVID-19, and in part because the success of COVID-19 mitigations can be amplified by integration with pre-existing safety systems. [1]

According to the Philippine Domestic Construction Board (PDCB), there are four (4) major components of the project cycle: Materials, Manpower, Machinery, and Money. [2] These four components are the necessary resources needed to operate a construction project. The continuity of a building project during a pandemic is dependent on the consistent availability of the project's main components. It is critical to developing health and safety procedures for construction-related activities. and Sciences Publication

(C) Copyright: All rights reserved.
Blue Eyes Intelligence Engineering

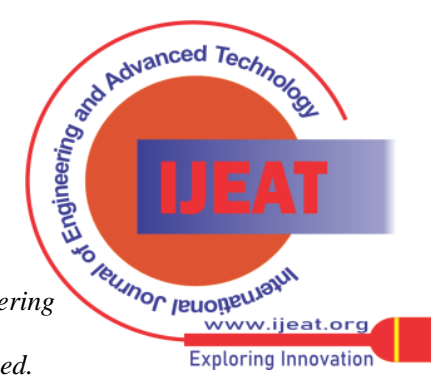


The Philippines' communities have high transmission rates, especially in the National Capital Region and surrounding areas such as Central Luzon. Several structures define the specific course of action that can be applied with each stage of transmission. The safety procedures for the project in the construction industry may vary based on local factors and transmission speed. We may use the degree of transmission, population features, and public health capability as variables in a given construction project workplace to analyze and review the situation to decide a potential course of action in the battle against COVID-19 transmission scenarios in government construction projects.

\section{METHODOLOGY}

The approaches to dealing with the pandemic made by government agencies may differ depending on the challenges encountered at present and the already done strategies. The policies can be broken down into three interrelated phases: Re-act, Re-assess and Re-build [3]. In the construction industry, the first made is to manage and ensure that there is an immediate response for the pandemic through analysis and survey of the current resources on materials, manpower, machinery, and money. The Re-act phase is simply an immediate response and a short-term plan during the construction phase on a pandemic.

The second phase is the Re-assess phase in which the protocols are formulated based on the initial reaction to the pandemic. The last phase is to focus on the recovery process of the agency. The consequences and impacts of the pandemic are still a threat to the rebuilding of the construction industry. This phase allows an opportunity to build a concrete plan and response preparedness for the sustainability and resilience of the construction project against a pandemic.

This paper will provide an assessment, evaluation, and recommendations on the current mandated rules of government agencies within Central Luzon in terms of safety and health guidelines in the implementation of construction projects during this Covid-19 public health crisis.

The research was carried out at government agencies and construction firms in Nueva Ecija that specialize in government infrastructure projects consisting of nine (9) contractor respondents, eleven (11) Local Government Units (LGU's) respondents, ten (10) respondents under NIA-UPRIIS, two (2) respondents under DILG and nine (9) respondents under DPWH Nueva Ecija for a total of 41 respondents.

This location was chosen to identify the New Normal Set-up on Safety and Health Standards in Government Projects in the occurrence of a Covid-19 pandemic at Central Luzon and also to become a basis of the revised guidelines of safety protocols in the field of a construction project under the government. Additionally, these guidelines will help them to cope up with this pandemic and whether they think these protocols help their company contain the virus in the construction of the project.

Through intensive analysis, the researchers have come up to form a survey questionnaire, consisting of nine (9) questions with different and expanded choices, to give the respondents broad ideas and help them select the best answer. The researchers made use of advanced online technology to create an online survey, using Google Forms. The researchers also used different online platforms such as Facebook,
Messenger, and Emails to spread the online survey to the target respondents, to obtain the necessary data needed to conduct this research.

\section{RESULTS}

There are two (2) indicating factors involved in determining the set-up of health and safety standards in government construction projects during this new normal era. The first factor consists of five (5) yes or no questions constructed positively. The second factor, which consists of four (4) questions provides selections for the respondents to help them choose the perfect approach the respondents' organization has provided. It was also sub-divided into four(4) categories, to maximize the data that can be gathered. The following graphs indicate the results of the respondents on each question.

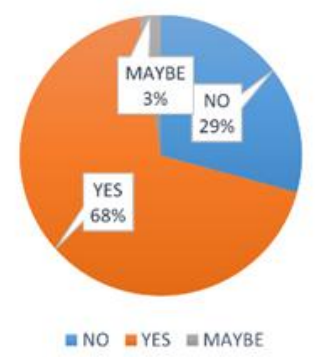

Fig. 1.Does your organization implement skeletal work force system?

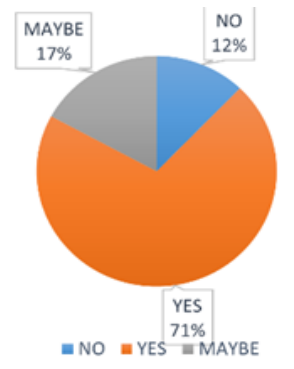

Fig. 2.Do you think your agency overcome the impact of this pandemic?

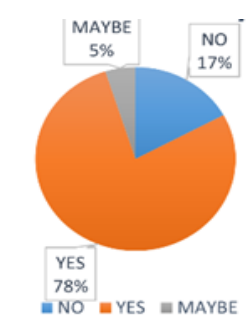

Fig. 3.Does your company provided medical assistance in the New Normal Workforce System?

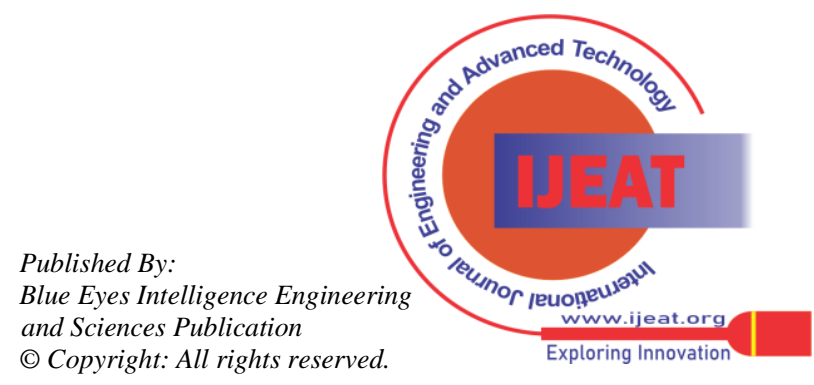




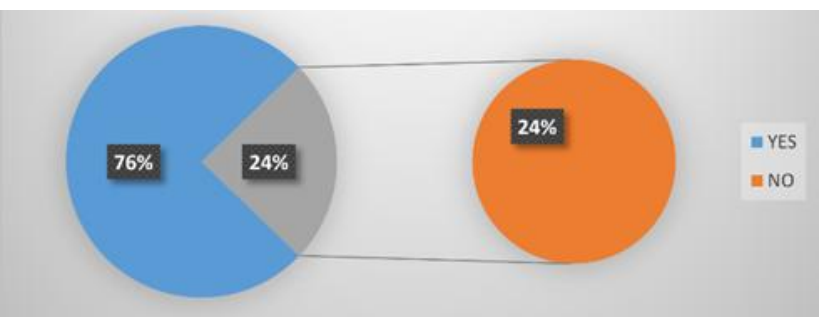

Fig. 4. Do the contractors/workers strictly follows this safety protocols implemented by your agency?

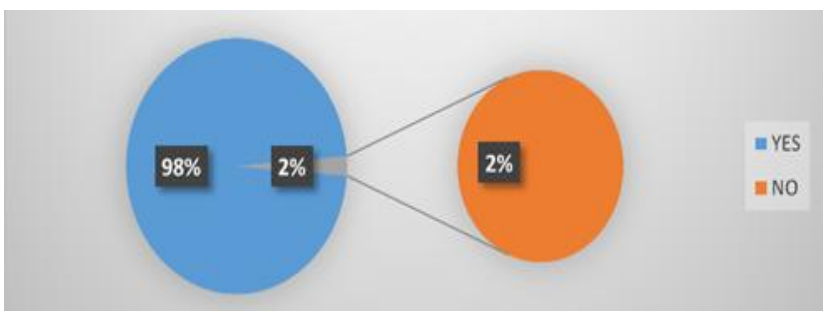

Fig. 5. Do you think this safety protocols implemented by your agency is effective from containing the spread of the virus in the workplace?

\section{CARGO IS UNLOADED ONLY BY THE RECEIVERS, WHILE THE DELIVERERS DO NOT LEAVE THEIR VEHICLES.; \\ - CaRGo UNDERGo proper disinfeCtion proceduREs beFore USE. INVOLVED STAFF ARE ALSO PROPERLY DISINFECTED BEFORE ENTERING THE. \\ ALL EQUIPMENT AND MATERIAL DELIVERIES ARE CAREFULLY PLANNED AND MONITORED. \\ $\sim$ TRANSITION AND DELIVERY ZONES ARE IDENTIFIED AND UIMITED TO SELECT PERSONNEL, I.E., RECEIVERS AND DELIVERERS. TRANSITION PERSONNEL ARE..

$-7 \quad$ SOCIAL DISTANCING AND OTHER PROTOCOLS BY THE DEPARTMENT OF
HEALTH (DOH) ARE FOLLOWED. HEALTH (DOH) ARE FOLLOWED.}

Fig. 6. What are the new normal set-up in your government agency for construction projects, in terms of deliveries?

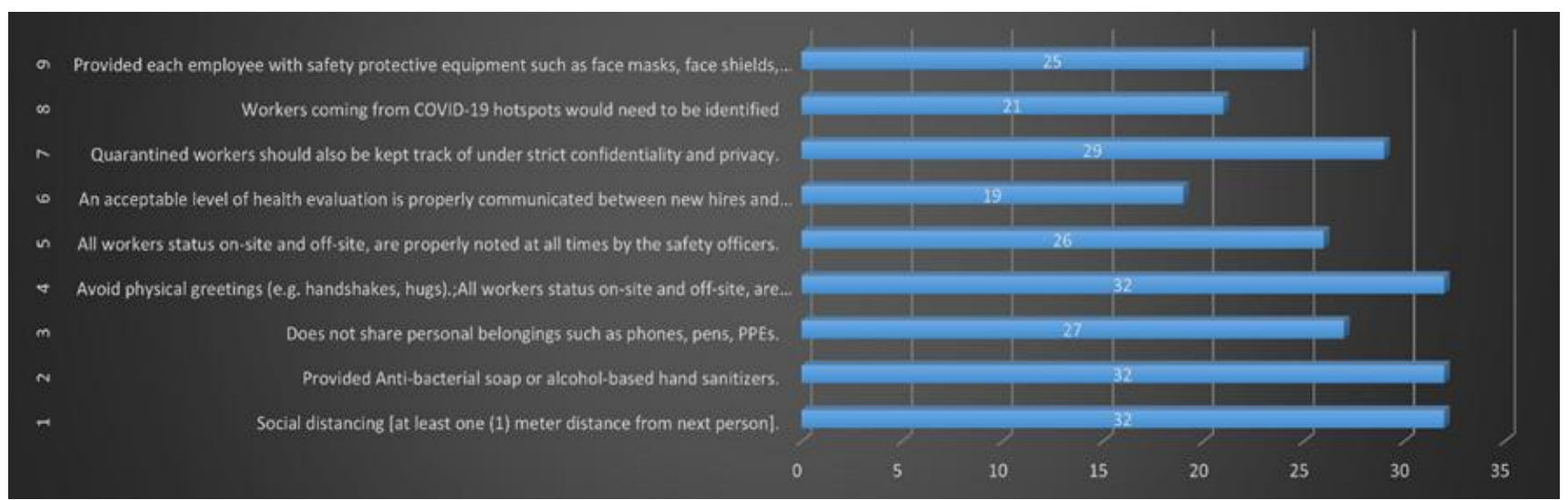

Fig. 7. What are the new normal set-up in your gveornment agency for construction projects in terms of Manpower Awareness and Communication?
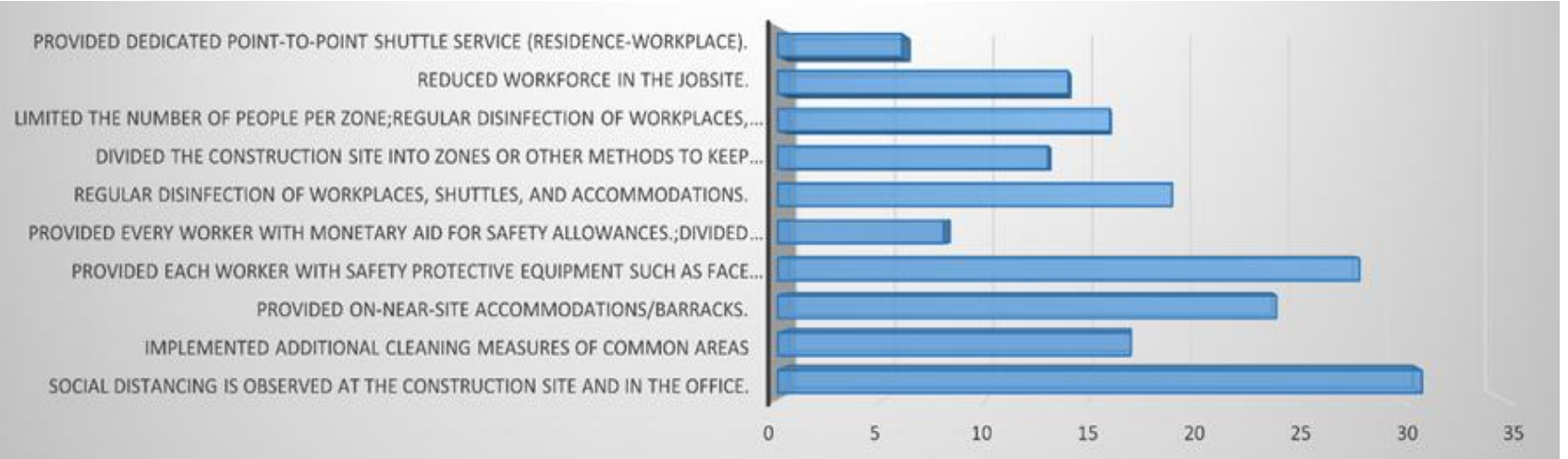

Fig. 8. What are the new normal set-up in your government agency for constrcution projects, in terms of Manpower in Site Operations/Construction Work Site?

Published By:

Blue Eyes Intelligence Engineering and Sciences Publication

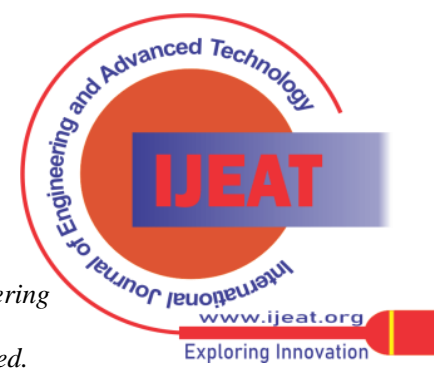




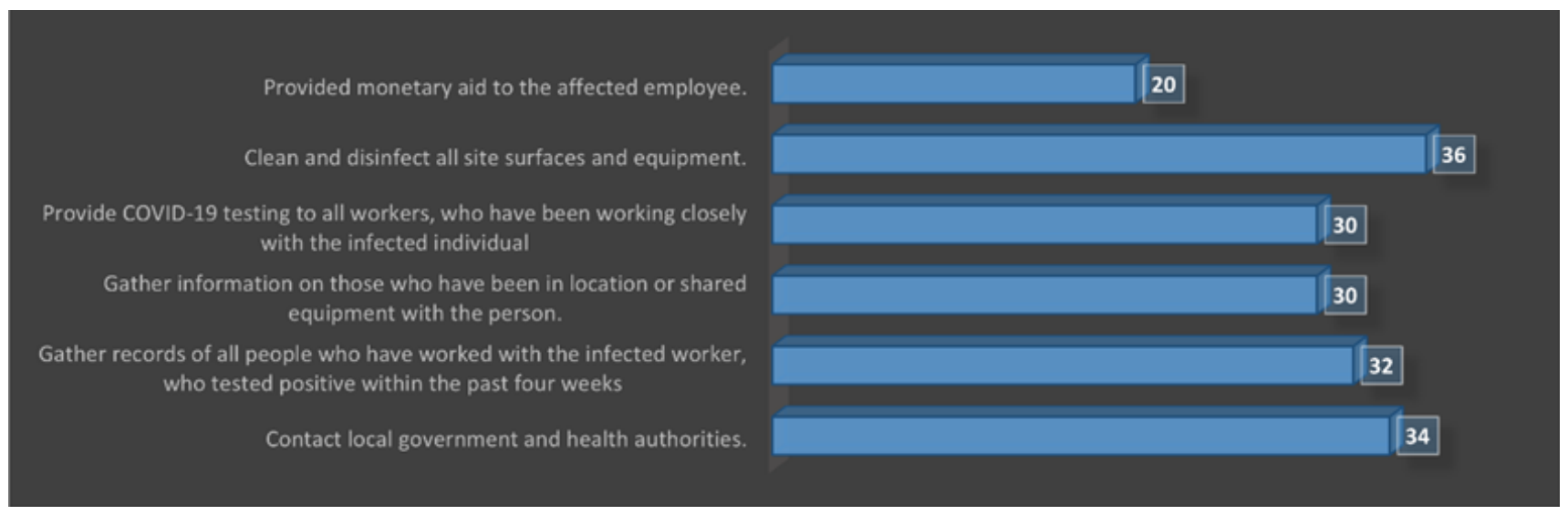

Fig. 9. What are the safety protocol if there is an employee who tested positive for Covid-19 virus?

\section{A. Does your company implement skeletal workforce system?}

Figure 1 illustrates that most of the respondents firmly agree that their organization implemented a skeletal workforce system, or the working system which filters a minimum number of employees needed to operate, or full staffing is not necessary, which amounts to $68 \%$, followed by respondents who disagree that their organization did not implement that policy, with a total percentage of $29 \%$. Additionally, 3\% of the respondents are unsure whether it was implemented or not.

\section{B. Do you think your agency overcome the impact of this pandemic?}

Figure 2 illustrates that most of the respondents believe that their organization did overcome the impact this pandemic has caused, which amounts to $71 \%$, followed by respondents who are quite unsure whether their organization did well during this pandemic, with a total percentage of $17 \%$. Additionally, $12 \%$ of the respondents believe that their organization did not do well in overcoming this pandemic.

C. Does your company provide employees with medical assistance in the New Normal Workforce System

Figure 3 illustrates that most of the respondents' agencies provided each employee with medical assistance, which amounts to $78 \%$, followed by respondents who stands that their company has not provided medical assistance during this pandemic, with a total percentage of $17 \%$. This policy was very important in this New Normal because everyone needed the assurance to be safe. Additionally, 5\% of the respondents are quite unsure whether the company has provided full medical assistance to all employees.

D. Do the contractors/workers strictly follow these safety protocols implemented by your agency?

Figure 4 illustrates that more than half of the respondents agree that their organization follows all the safety protocols provided by the IATF and other government agency, which amounts to $76 \%$ followed by respondents who answered that their organization did not follow the protocols for health and safety, with a total percentage of $24 \%$.

E. Do you think the safety protocols implemented by your agency is effective from containing the spread of virus in the workplace?

Figure 5 shows that the organization has put in place safety precautions to prevent the virus from spreading in their workplace. The percentage of respondents who said yes was $98 \%$, while just $2 \%$ thought their organizations' policies were ineffective in limiting the infection.

\section{F. New Normal Set-Up in Government Agency for Construction Projects - in terms of Deliveries}

Figure 6 depicts various means and techniques that their relevant agency adopts to the new normal set-up in a government agency. The vertical axis reflects the number of respondents, while the horizontal axis reflects the tools and strategies used by their agency to support this new normal in their project. The graph shows social distancing and other Department of Health and DPWH protocols as the dominating choice, with a total of 40 options.Next in line is that all equipment and material deliveries are carefully planned and monitored, which garnered 28 selections. The third choice was that the transition and delivery zones were identified and limited to selected personnel, resulting in 16 selections. While other means and methods such as cargo are unloaded only by the receivers, and cargo undergoes proper disinfection procedures receive 9 and 2 selections, respectively.

G. New Normal Set-Up in Government Agency for Construction Projects - in terms of Manpower Awareness and Communication

Figure 7 shows the new normal set-up in terms of manpower and awareness. The graph presents social distancing and other protocols by the Department of Health and Department of Public Works and Highways is still the dominant choice, but together with the provision of anti-bacterial soaps or alcohol-based sanitizers, and the avoidance of physical greeting, with values amounting to 32 selections. The second choice was that all quarantined workers were kept tracked under strict confidentiality, which obtained 29 selections. Next is that employees/worker does not share their personal belongings to co-workers, which garnered 27 selections. The fourth choice was all workers status on-site and off-site are properly noted, which results in 26 selections.

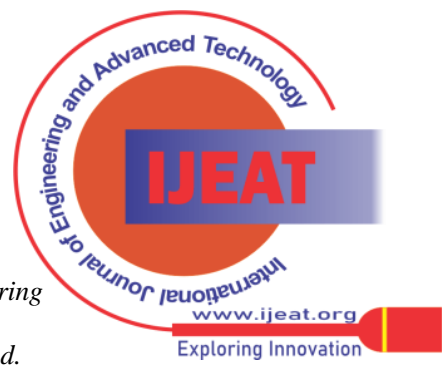


Fifth on the list was their agency provided each employee with safety protective equipment such as face masks and face shields, which obtained 25 selections. Lastly, workers coming from COVID-19 hotspots are identified, and that an acceptable level of health evaluation is properly communicated between new hires and management receives the least selections, 21 and 19 selections, respectively.

\section{H. New Normal Set-Up in Government Agency for Construction Projects - in terms of Manpower in Site Operations/ Construction Worksite}

Figure 8 shows the respondents' selections of how their agency copes up in terms of manpower in site operations. It is always clear that the most implemented and followed rule is to observe social or physical distancing which results in 31 selections. Second on the list of which receives the highest selections was to provide employees and workers with safety protective equipment, garnering 28 votes. The two least selected method was that agencies provided monetary aid for safety allowances, which only achieves 8 votes, and provision of dedicated point-to-point shuttle service which only gathered 6 selections. Other aids and measures were also listed, such as the provision of near-site accommodations or barracks, obtaining 24 votes, regular disinfection of workplaces and accommodations having 19 selections, implementation of additional cleaning measures of common areas which had 17 votes, a limited number of people per zone with 16 selections, reduction of workforce in job site with 14 and division of construction site into zones which receives to 14 selections.

\section{Safety Protocols for Employees who Tested Positive for COVID-19 Virus?}

Figure 9 indicates the means and methods the organization has provided for those who tested positive for COVID-19. Dominating the list was to clean and disinfect all site surfaces and equipment, which receives 36 selections. Next to that was to contact local government authorities regarding the situation, obtaining 34 selections. Third on the spot was to gather records of all people who have worked with the infected worker, or contact tracing method, which receives 32 votes. Tied on the fourth spot was to gather the location on which the infected has been and the equipment used, and to provide COVID-19 testing to people with close contact with the infected worker, garnering 30 votes. Last on the list was providing monetary aid to the affected employee, which obtains 20 selections.

\section{FUTURE WORK}

In this study, we discuss the New Normal Set-Up on Safety and Health Standards in Government Construction Projects at Nueva Ecija: A Case of Covid-19, in which we discovered how the government sector responded to the changes brought about by the pandemic. We can utilize this as a foundation in the future to better the way we respond in the event of a pandemic especially in the construction industry.

\section{CONCLUSION}

This study verified the effectivity of Philippines' New Normal Set-up on Safety and Health Standards in Government Construction Projects during a pandemic crisis through the corresponding survey and questionnaires conducted by the researchers. The researchers identified the

Three (3) interrelated phases to manage and ensure that there is an immediate response for the pandemic through analysis and survey of the current resources on materials, manpower, and machinery. The result shows that these safety precautions followed by different government agencies are effective in containing the spread of the virus in a construction workplace.

\section{REFERENCES}

1. Stiles, S., Golightly, D., \&amp; Ryan, B. (2021, January 12). Impact of COVID-19 on health and safety in the construction sector. Wiley Online

https://onlinelibrary.wiley.com/doi/10.1002/hfm.20882

2. Construction Guidelines for Project Implementation during the period of Public Health Emergency (n.d.) https://www.gppb.gov.ph/assets/pdfs/Construction\%20Guidelines $\% 2$ 0for\%20Project\%20Implementation.pdf.

3. Public procurement and infrastructure governance: Initial policy responses to the coronavirus (Covid-19) crisis. OECD. (2020, July 30). https://www.oecd.org/coronavirus/policy-responses/public-procureme nt-and-infrastructure-governance-initial-policy-responses-to-the-coro navirus-covid-19-crisis-c0ab0a96/.

\section{AUTHORS PROFILE}

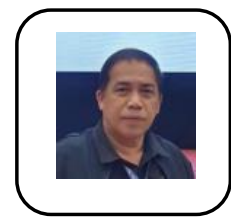

Noel T. Florencondia, Licensed Professional Electrical Engineer, Former Dean and Chairman of the College of Engineering at Nueva Ecija University of Science and Technology. Professor IV academic ranked. Active member of Institute of Integrated Electrical Engineers of the Philippines, Inc. A resource person of various technical and professional seminars. An author of many research paper published in a Scopus indexed and other reputable scientific and international journals.

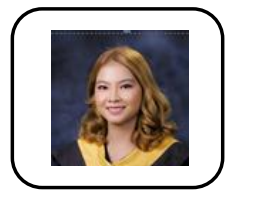

Rhizza Mae B. Lansangan, BS in Civil Engineering, senior engineer A at National Irrigation Administration - UPRIIS Division V. She has 2 years of experience of working in NIA. She can be reached at rhizzamaelansangan@gmail.com

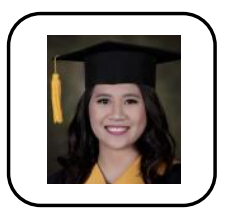

Ericka V. Marcos, BS in Civil Engineering, Instructor II at Araullo University - Phinma Education Network, College of Information Technology and Engineering. She has 6 months experience in teaching and 1 year experience as QS Engineer at St. Claire Builders Inc. She can be reached at erickamarcos1022@gmail.com

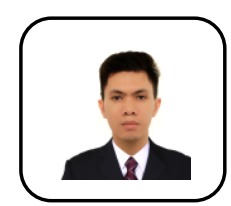

John Vincent L. Santos, BS in Civil Engineering, Lecturer II at Holy Cross College, Education Department. He has 1 year experience in teaching undergraduate classes. He can be reached at j.vince103@gmail.com

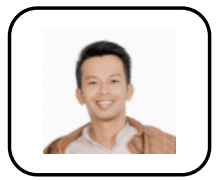

Keith Russel E. Soriano, BS in Civil Engineering, senior engineer A at National Irrigation Administration - UPRIIS Division IV. He has 2 years of experience of working in NIA. He can be reached at keithsoriano.krs@gmail.com

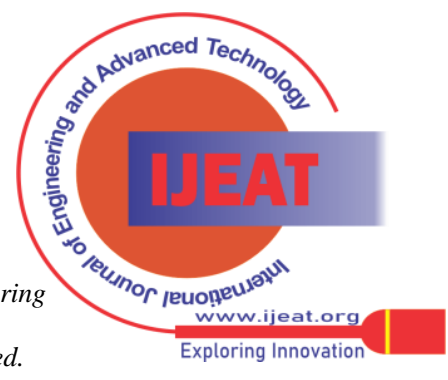

